Research Article

\title{
Foaming Behavior and Pore Structure Evolution of Foamed Aluminum under the Extrusion Constraint
}

\author{
Lucai Wang $\mathbb{D},{ }^{1}$ Yanli Wang $\mathbb{D},^{2}$ Xiaohong You $\mathbb{D},{ }^{1}$ and Fang Wang $\mathbb{D}^{1}$ \\ ${ }^{1}$ College of Materials Science and Engineering, Taiyuan University of Science and Technology, Taiyuan, China \\ ${ }^{2}$ College of Materials Science and Engineering, North University of China, Taiyuan, China \\ Correspondence should be addressed to Yanli Wang; 443976393@qq.com
}

Received 27 May 2020; Revised 3 November 2020; Accepted 10 December 2020; Published 22 December 2020

Academic Editor: Yue Hou

Copyright (c) 2020 Lucai Wang et al. This is an open access article distributed under the Creative Commons Attribution License, which permits unrestricted use, distribution, and reproduction in any medium, provided the original work is properly cited.

This study evaluates foaming behavior and pore structure evolution of aluminum foam by cross-sectional image processing, which was prepared by the powder compact melting (PCM) method under the constraint. The results revealed that the heating time and the heating rate are the key factors affecting the foaming behavior and pore structure of aluminum foam. The thermal decomposition of the foaming agent and aluminum melting behavior affect the foam expansion under different heating times and heating rates. The evolution of the pore structure during the foaming process includes pore formation, small-sized spherical pores, large-sized spherical pores, polygonal pores, merging, and collapse. Due to the limitation of the pipe wall, the maximum expansion height and porosity are constrained, and the macrostructure of aluminum foam is improved.

\section{Introduction}

As the representative of metal foam materials, aluminum foam has the advantages of low density, strong impact absorption, high temperature resistance, flame retardancy, corrosion resistance, sound insulation and noise reduction, low thermal conductivity, excellent weather resistance, and good electromagnetic shielding performance. Aluminum foam products have the advantages of convenient processing and installation, high molding precision, surface coating, reusability, recycling, and so on, and have many potential applications. Therefore, they have attracted wide attention in science and industry [1-8].

With the establishment of the research and development center for aluminum foam by Ethyl Corporation in the 1960s, aluminum foam has been successfully applied in sound absorption, noise reduction, and collision prevention including carriages and containers, bumpers and silencers, thermal insulation walls and fire doors, and energy-saving movable houses [9-11]. However, as structural materials with most application potential, relatively speaking, it has not made much progress. The aluminum foam-filled pipe exhibits lightweight characteristics and high specific stiffness, as well as excellent vibration damping and damping properties. The filling structure solves the issue of low strength when completely utilizing the characteristics of aluminum foam materials [12-15], considerably extending the applications of aluminum foam.

The aluminum foam-filled hollow pipe prepared by the powder compact melting (PCM) extrusion method exhibits advantages of a simple process, facile operation, and facile adaptability to irregular parts with different structures; hence, aluminum foam has become attractive for research both domestically and internationally [7, 16-20]. Internationally, the process has developed rapidly and entered the stage of large-scale industrial production. On the contrary, in domestic countries, although some progress has been made, the preparation process is still the most basic problem. In $[21,22]$, precursor samples have been typically prepared by cold pressing, hot pressing, and extrusion. The results revealed that a more dense, uniform precursor structure is prepared by the extrusion method. In the study, aluminum foam inside the pipe was prepared by the PCM method by extrusion, and the foaming behavior and pore structure evolution of aluminum foam in the hollow pipe were investigated to clarify the relation variation and formation 
mechanism among the process conditions, sample temperature, foaming behavior, and pore structure, which laid a foundation for the further development and application of aluminum foam.

\section{Sample Preparation}

2.1. Preparation of the Foamable Precursors. The first step of the phase-change material method is to produce foamable precursors. It mainly includes three steps: (1) powder mixing: the two powders were evenly mixed in a four-head planetary ball miller, that is, $\mathrm{Al}$ (99.5 wt.\%, technically pure (99.9\%), and 300 mesh) and powdery foaming agent $\mathrm{TiH}_{2}$ (0.5 wt.\%, 99.6\%, and 300 mesh). (2) Cold pressing: the mixture was cold pressed into a cylindrical preform of $934 \mathrm{~mm}$ and $40 \mathrm{~mm}$ by a servo hydraulic press at $300 \mathrm{MPa}$ so that the density of the precursor is greater than $90 \%$ of the bulk density. (3) Hot extrusion: the preform was placed in the corresponding mold and heated to $500^{\circ} \mathrm{C}$ and kept for $25 \mathrm{~min}$. Under the pressure of $250 \mathrm{MPa}$ applied by the hydraulic press, the cylindrical preform was transformed into a cylindrical belt with a size of $\Phi 10 \mathrm{~mm}$ and $300 \mathrm{~mm}$ and was called a foamable precursor. Then, the small granulates of $\Phi 10 \mathrm{~mm}$ and $50 \mathrm{~mm}$ were cut by a wire electrical discharge machining (WEDM) system (Figure 1(a)).

\subsection{Production of the Aluminum Foam-Filled Stainless Pipe.} The second step of the PCM method is foaming the foamable precursor. The constrained foaming method was employed for the foaming of the precursor samples in the hollow pipe. (4) Heating the pipe: the small precursor (Figure 1(a)) was put in the hollow pipe at $760 \sim 800^{\circ} \mathrm{C}$ for $6 \sim 7 \mathrm{~min}$ in a horizontal resistance furnace (Figure 1(b)). (5) Foaming: in decomposition of $\mathrm{TiH}_{2}$, the precursor foams to fill the pipe. (6) Accelerated cooling: it was taken out and rapidly cooled using an atomizing spray.

The effects of the foaming process and foaming of the same sample at different heating rates (furnace temperatures) were investigated. The precursor samples were put into a hollow steel pipe, heated, and foamed at a specific furnace temperature. In order to compare the foaming characteristics and filling compounding of foamed aluminum in the steel pipe with different initial cross-section ratios, the hollow pipes used have two diameters.

Table 1 summarizes the detailed process plan.

\section{Experimental Results}

Two thermocouples were used to measure the furnace temperature and the temperature of the sample, and the temperature and time were recorded by a data acquisition instrument and a computer (Figure 1(b)). The pictures were taken by the digital camera, and the foaming process of the sample was recorded in real-time penetrating quartz glass, and then the expansion height (and expansion height ratio) was calculated. Expansion height $(H)$ is the height of the maximum expansion of each foaming time sample; expansion height ratio $\left(H_{\mathrm{r}}\right)$ is the ratio of the maximum expansion height of the sample to the original diameter of the sample during the foaming time.

3.1. Expansion and Foaming Behavior of the Sample at Different Furnace Temperatures. Figure 2 shows the variation in the temperature and expansion height of the sample in pipe $\mathrm{A}$ as a function of the heating time at furnace temperatures of $760^{\circ} \mathrm{C}$ and $800^{\circ} \mathrm{C}$ (referred to as the temperature riseexpansion curves). Figure 3 shows the temperature riseexpansion curves of the sample in pipe B at furnace temperatures of $740^{\circ} \mathrm{C}$ and $760^{\circ} \mathrm{C}$. Figure 4 shows the ten stages of foaming behavior of the sample in pipe $\mathrm{A}$ at a furnace temperature of $800^{\circ} \mathrm{C}$, where (a) not foaming; (b)-(d) early expansion; (e) and (f) pore growth; (g) filled the cross section of the steel pipe; (h) expanding to the maximum point; and (i) and (j) the pores merge and collapse.

\subsection{Evolution of the Sample Pore Structure at Different Fur-} nace Temperatures. According to the heating curves, five to six heating time points are selected from each furnace temperature, and five to six substantially identical samples are heated to the corresponding time points, rapidly removed, cooled, cut, and photographed. Figure 5 shows the pore structure evolution of the sample in pipe $A$ at a furnace temperature of $800^{\circ} \mathrm{C}$. For the samples in pipe A obtained at different furnace temperatures, Figures 6 and 7 summarize their variations in the cross-sectional photographs, the corresponding binarization-treated diagram, porosity $P_{0}$, average equivalent-circle diameter $D_{a}$, and average circularity $C_{a}$ at different temperatures. The situations in pipe $\mathrm{B}$ are similar to these and will not be described again.

\section{Results and Analysis}

4.1. Effects of Heating Time (Sample Temperature). For the experiments with the aluminum foam-filled composite pipe, the complete filling of a steel pipe constitutes a condition that must be satisfied. Therefore, the samples listed in Table 2 are all the samples that have achieved the full filling condition (sample temperatures $>700^{\circ} \mathrm{C}$ ). Although there is no significant difference in the expansion and foaming behavior of each sample, the porosity and pore structure still change with temperature. According to Figures 2 and 3, the relationship between the expansion height ratio and temperature of the sample is plotted and is shown in Figure 8. The combination of Figures 2-5 revealed that the sample temperature increases with the extension of the heating time (when the furnace temperature is constant, the two values correspond to each other) and comprises three stages: temperature rise, melting plateau, and second temperature rise. The expansion curve comprises several stages, including zero expansion (before the temperature plateau); slow expansion (plateau zone); rapid expansion (after the temperature plateau); maximum value; and collapse. The pore structure in the foaming process has experienced a stage evolution process, including pore formation, small-sized spherical pores, large-sized spherical pores, polygonal pores, merger, and collapse. 


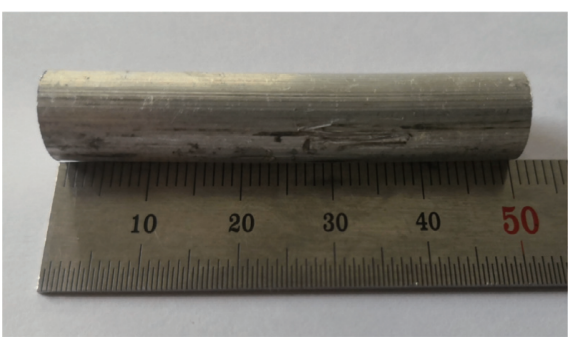

(a)

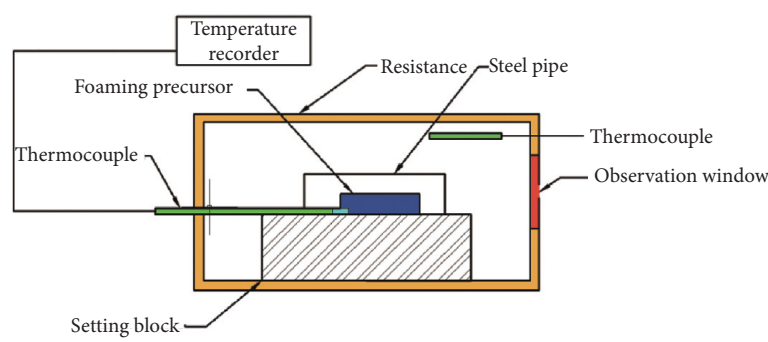

(b)

Figure 1: (a) Rod-like precursor prepared by extrusion and (b) schematic of heating the precursor under the in-pipe constraint.

TABLE 1: Schematic of the foaming process of a single precursor pipe.

\begin{tabular}{|c|c|c|c|c|c|c|}
\hline \multirow[b]{2}{*}{ Conditions } & \multicolumn{2}{|c|}{ Process parameters } & \multicolumn{4}{|c|}{ Structure parameters } \\
\hline & $\begin{array}{c}\text { Furnace temperature } \\
\left({ }^{\circ} \mathrm{C}\right)\end{array}$ & $\begin{array}{l}\text { Heating rate } \\
\left({ }^{\circ} \mathrm{C} \cdot \mathrm{s}^{-1}\right)\end{array}$ & $\begin{array}{l}\text { Pipe diameter } \\
(\mathrm{mm})\end{array}$ & $\begin{array}{l}\text { Wall thickness } \\
(\mathrm{mm})\end{array}$ & $\begin{array}{c}\text { Length } \\
(\mathrm{mm})\end{array}$ & Section ratio (\%) \\
\hline Steel pipe & 760 & 3.9 & 25 & 0.7 & 90 & 0.2 \\
\hline A & 800 & 4.4 & & & & \\
\hline Steel pipe & 740 & 3.9 & 23 & 0.7 & 90 & 0.26 \\
\hline $\mathrm{B}$ & 760 & 3.9 & & & & \\
\hline
\end{tabular}

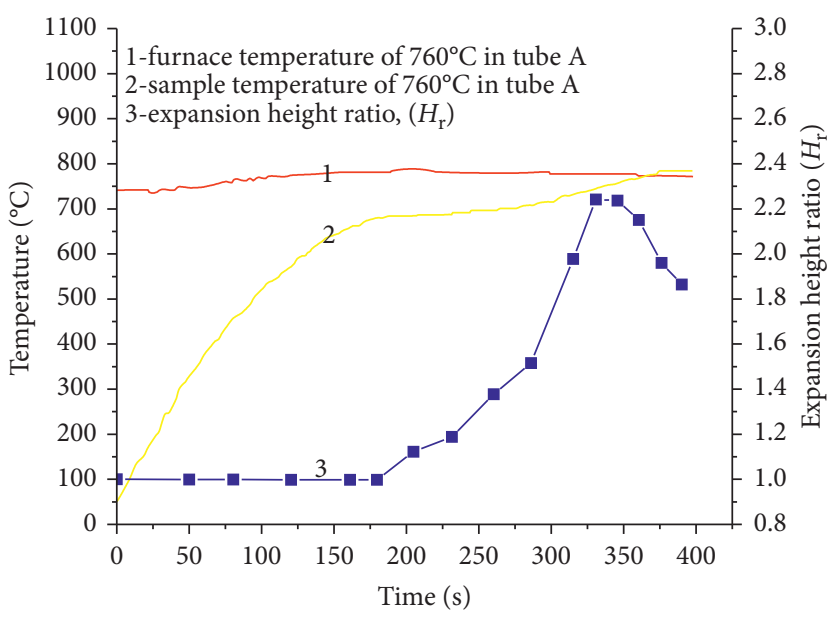

(a)

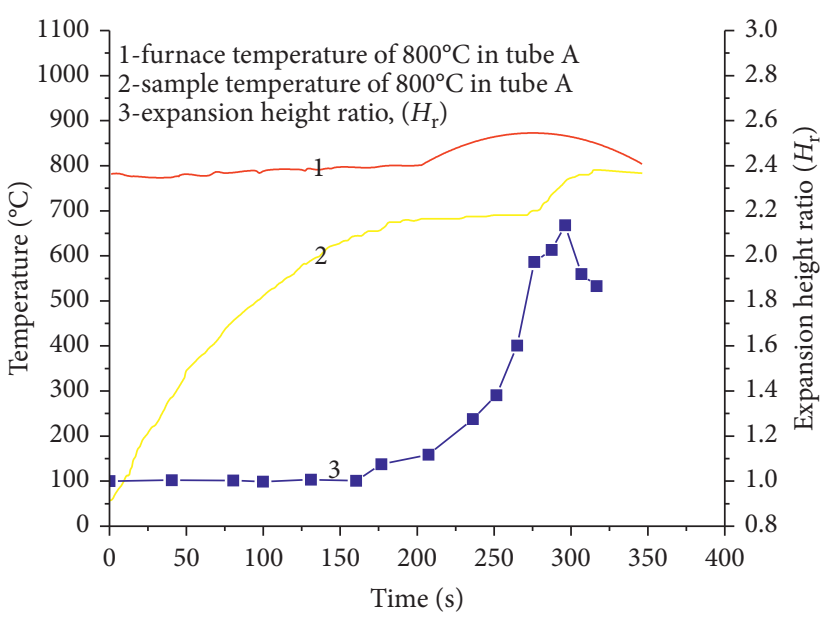

(b)

Figure 2: Temperature rise-expansion curves of the sample in pipe A at furnace temperatures of $760^{\circ} \mathrm{C}$ (a) and $800^{\circ} \mathrm{C}(\mathrm{b})$.

It can be seen from Figures 6 and 7 that when the foaming process is constrained, the pore structure continues to change with increasing temperature after the foam completely fills the steel pipe. Therefore, the porosity has experienced the process of rising; maximum value; and reduction. However, the pore size shows two processes: regular growth of a single pore and merge growth. The average diameter is constantly increasing, the circularity of the pores tends to decrease, but the change rule is unclear. During the process of merger and growth, serious deterioration occurred.

Compared with the results reported previously [21], during the foaming process under the in-pipe constraint, the heating rate of the sample is greater than that of free foaming, and the sample temperature can reach or exceed the furnace temperature, probably as the heat released during the melting of the sample cannot dissipate on time. Owing to the limitation of the pipe diameter, the maximum expansion height and porosity are constrained, while the pore size, shape uniformity, and circularity of pores are better than those during free foaming. In addition, the transverse expansion process is observed after the steel pipe is filled with the sample. Therefore, after full filling, the porosity continues to increase. The combination of Figures 6-8 indicated that, in the case of constrained foaming, the foaming effect with a porosity range of $70 \%-$ $79 \%$ and different pore structures can be obtained at a temperature range of $700^{\circ} \mathrm{C}$ to $750^{\circ} \mathrm{C}$, where the foaming effect is optimum for a certain temperature. The range of foaming temperature, the best foaming temperature, the 


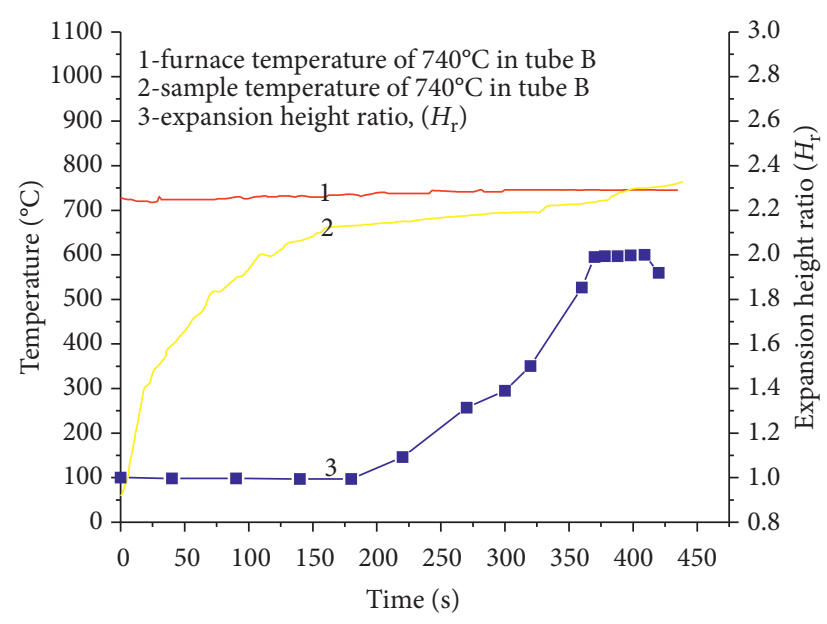

(a)

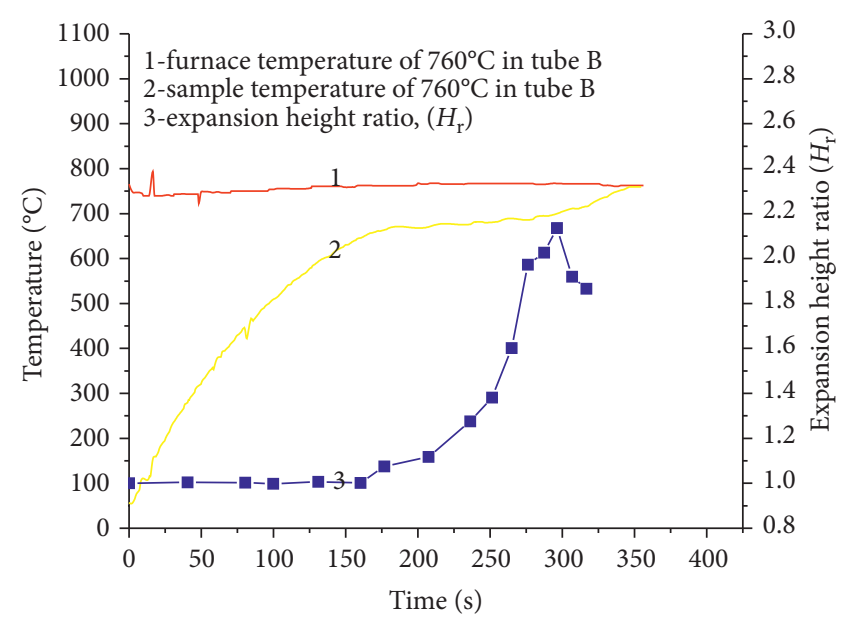

(b)

Figure 3: Temperature rise-expansion curves of the sample in pipe $\mathrm{B}$ at furnace temperatures of $740^{\circ} \mathrm{C}(\mathrm{a})$ and $760^{\circ} \mathrm{C}(\mathrm{b})$.

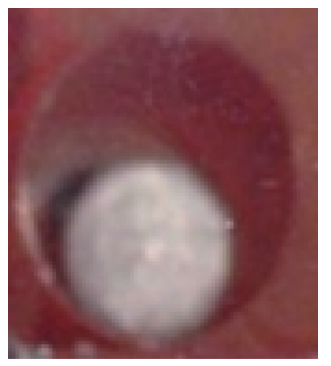

(a)

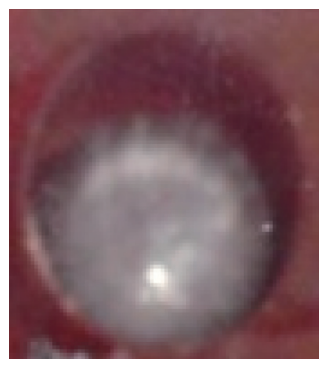

(f)

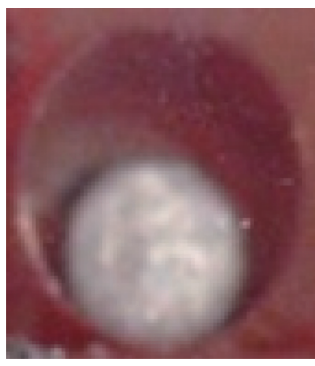

(b)

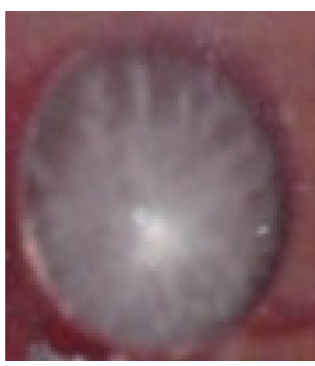

(g)

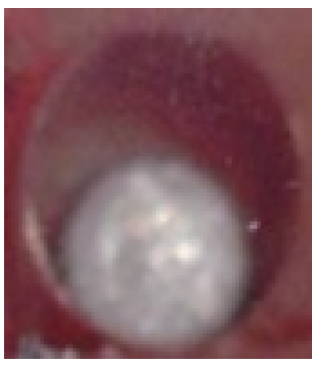

(c)

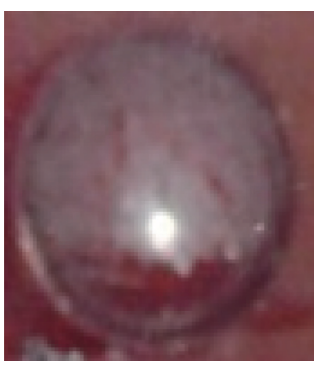

(h)

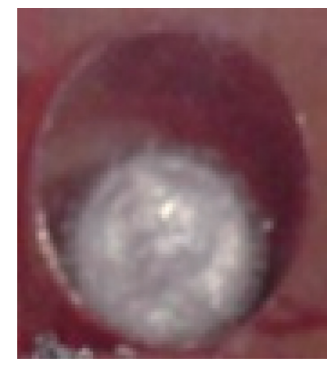

(d)

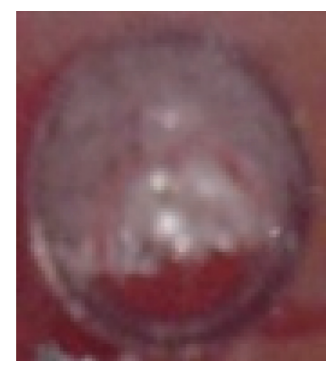

(i)

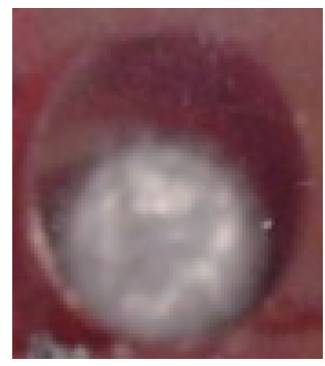

(e)

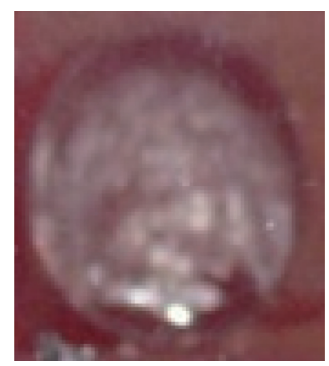

(j)

Figure 4: Foaming behavior in pipe A: (a) $255 \mathrm{~s}, 678.8^{\circ} \mathrm{C}$; (b) $270 \mathrm{~s}, 682.6^{\circ} \mathrm{C}$; (c) $285 \mathrm{~s}, 686.4^{\circ} \mathrm{C}$; (d) $300 \mathrm{~s}, 692.5^{\circ} \mathrm{C}$; (e) $310 \mathrm{~s}, 700.0^{\circ} \mathrm{C}$; (f) $320 \mathrm{~s}$, $709.2^{\circ} \mathrm{C}$; (g) $330 \mathrm{~s}, 718.6^{\circ} \mathrm{C}$; (h) $340 \mathrm{~s}, 733.1^{\circ} \mathrm{C}$; (i) $350 \mathrm{~s}, 748.2^{\circ} \mathrm{C}$; (j) $360 \mathrm{~s}, 760.3^{\circ} \mathrm{C}$.

range of porosity, and the maximum porosity are also different due to different heating rates.

\subsection{Effects of the Heating Rate (Furnace Temperature)}

\subsubsection{Effects of the Heating Rate on the Temperature Rise and} the Characteristic Value of the Expansion Foaming Process. The above experimental results indicated that different heating rates have basically the same heating and foaming expansion rules, but the characteristic parameters are obviously different (Table 2).
In-pipe constrained foaming and free foaming are similar [21]. Different furnace temperatures result in different heating curves of samples. The higher the furnace temperature, the earlier the moment to enter the plateau and the shorter the plateau length. On the contrary, the lower the furnace temperature, the later the time to enter the plateau and the longer the plateau length; however, the difference in the plateau length is less than that of free foaming. At each furnace temperature, the sample can fill with steel pipes. For the same steel pipe, the expansion rate is the same, and the temperature of the sample filled with the pipe is basically the same. The higher the furnace temperature, the larger the 


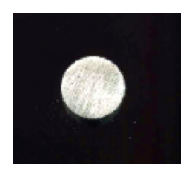

(a)

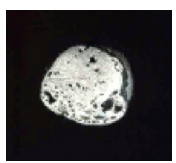

(b)

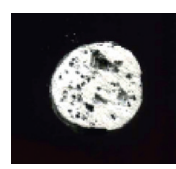

(c)

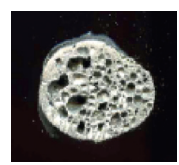

(d)

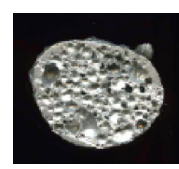

(e)

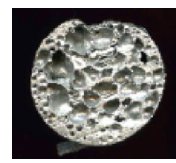

(f)

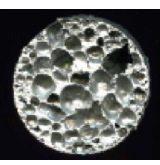

(g)

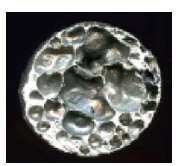

(h)

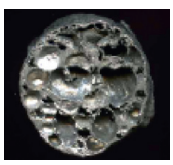

(i)

FIgURE 5: Expansion and foaming process of aluminum foam and its pore structure evolution.

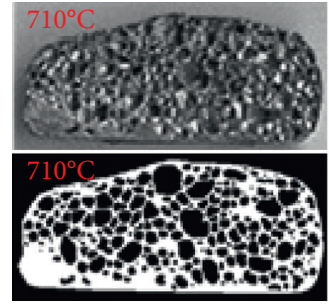

$P_{0}=69.8 \%$

$D_{\mathrm{a}}=2.147$

$C_{\mathrm{a}}=0.835$
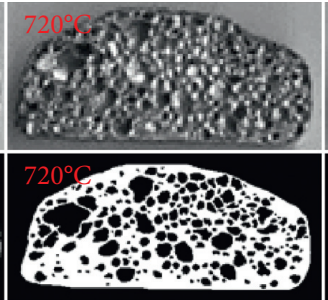

$P_{0}=72.8 \%$

$D_{\mathrm{a}}=2.104$

$C_{\mathrm{a}}=0.814$
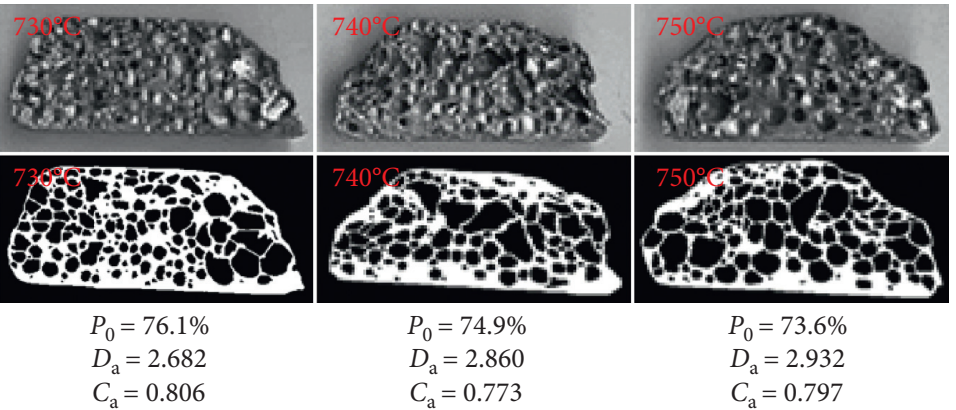

Figure 6: Cross-sectional macrographs of foams in tube A on the five sample temperatures at furnace temperature $760^{\circ} \mathrm{C}$.

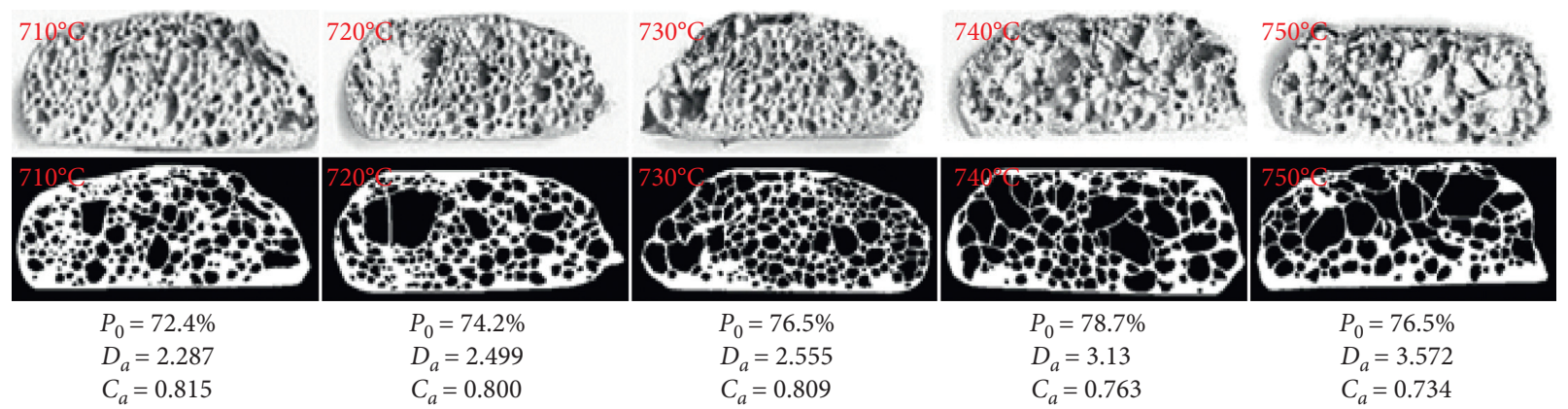

Figure 7: Cross-sectional macrographs of foams in tube $\mathrm{A}$ on the five sample temperatures at furnace temperature $800^{\circ} \mathrm{C}$.

maximum porosity of the sample. There is little difference in porosity, and the maximum porosity temperature is basically the same. The collapse temperature of the sample at different furnace temperatures is basically the same.

The heating rate of the in-pipe constrained foaming is significantly greater than that of the free foaming method [21] at the same furnace temperature, but the porosity at the same sample temperature is comparable to or slightly less than that of free foaming. The heating rate is greater than that of free foaming, possibly related to the homogenizing effect and heat insulation of the steel pipe, and the slightly lower porosity may be related to the inhibition effect of the steel pipe wall. Due to the influence of the steel pipe on the heating rate, the furnace temperature is no longer the only factor affecting the heating rate. On the contrary, the steel pipe also exhibits a certain inhibition on the decomposition and hydrogen evolution of $\mathrm{TiH}_{2}$. Therefore, the effect of furnace temperature on the expansion and foaming characteristic parameters during the in-pipe constrained foaming process decreases, but the effect of the sample temperature is more significant. The in-pipe constrained foaming process can achieve foaming at lower furnace temperatures.

The temperature at which the sample begins to collapse at different furnace temperatures is basically consistent under the in-pipe constraint, and it is basically the same as that in the free foaming process. The result indicated that the sample temperature and viscosity play essential roles during the collapse. The comparison between pipe B and pipe A indicated that the lower section ratio of pipe $B$ makes the sample completely fill the steel pipe earlier, indicative of a better filling effect and a lower temperature for complete filling. However, due to the great resistance caused by the pipe wall, the maximum porosity is also low. 


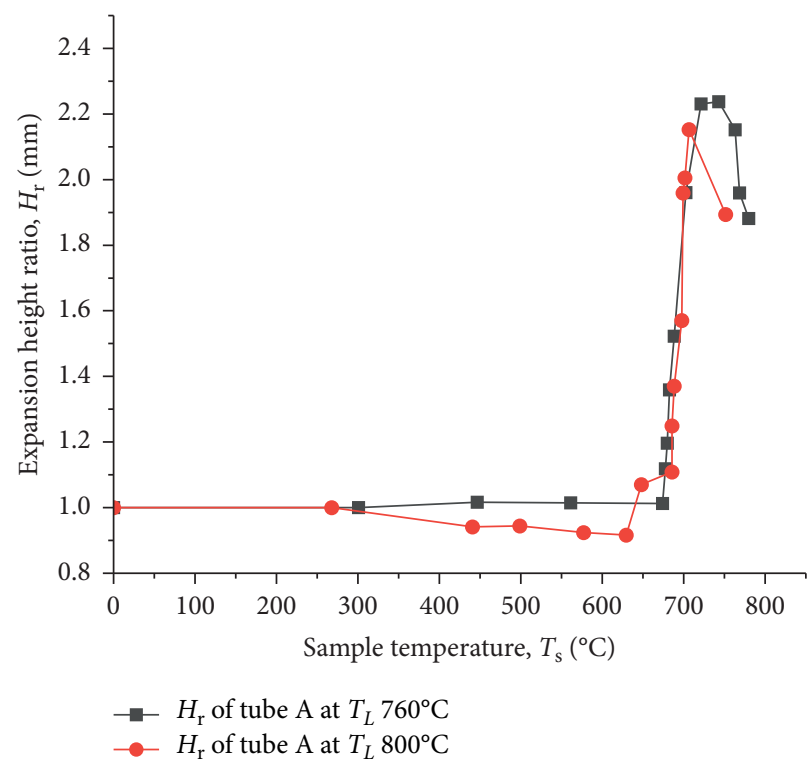

(a)

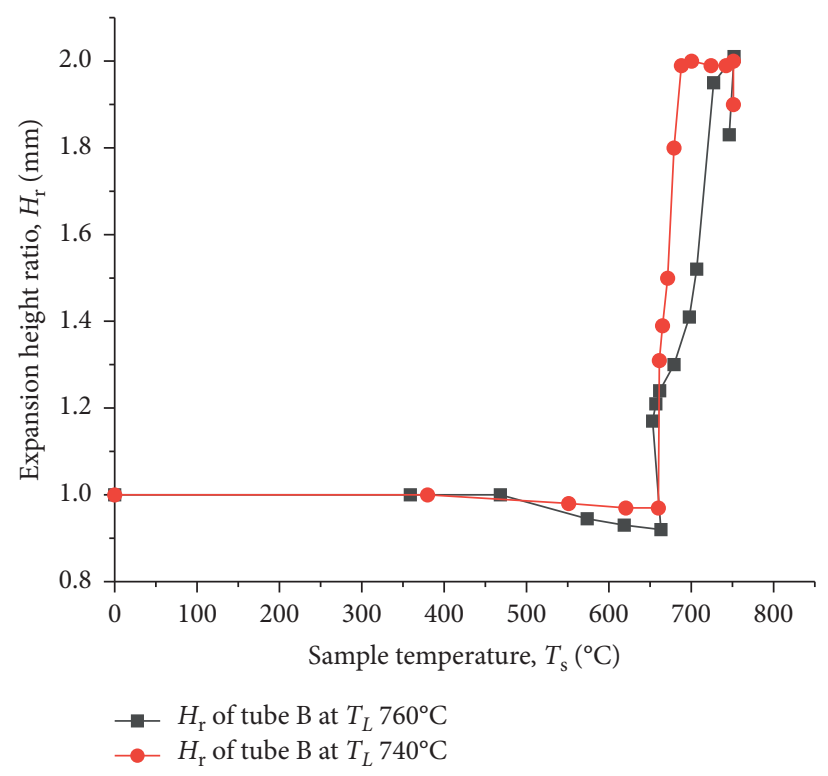

(b)

Figure 8: Relationship between the temperature and expansion height ratio of the sample in pipe A (a) and pipe B (b) at different furnace temperatures.

TABLE 2: Heating, foaming, and expansion parameters of samples at different furnace temperatures.

\begin{tabular}{|c|c|c|c|c|c|}
\hline \multirow{2}{*}{\multicolumn{2}{|c|}{$\begin{array}{c}\text { Furnace temperature, } T_{L}\left({ }^{\circ} \mathrm{C}\right) \\
\text { Characteristic parameters }\end{array}$}} & \multicolumn{2}{|c|}{ Pipe A } & \multicolumn{2}{|c|}{ Pipe B } \\
\hline & & 800 & 760 & 760 & 740 \\
\hline \multirow{2}{*}{\multicolumn{2}{|c|}{$\begin{array}{l}\text { Time to enter the plateau zone } \\
\text { Time length of the plateau zone (s) }\end{array}$}} & 150 & 170 & 170 & 170 \\
\hline & & $<100$ & 100 & 100 & 150 \\
\hline \multirow{3}{*}{ Filling point } & Time (s) & 320 & 345 & 330 & 370 \\
\hline & Temperature, $T_{\mathrm{s}}\left({ }^{\circ} \mathrm{C}\right)$ & 725 & 727 & 719 & 718 \\
\hline & Expansion height ratio, $H_{\mathrm{r}}(\mathrm{mm})$ & 2.3 & 2.3 & 2.0 & 2.0 \\
\hline \multirow{2}{*}{ Maximum expansion point } & Temperatures, $T_{\mathrm{s}}\left({ }^{\circ} \mathrm{C}\right)$ & 740 & 730 & 740 & 740 \\
\hline & Porosity, $P_{0}(\%)$ & 78.7 & 76.1 & 74.4 & 75.1 \\
\hline \multirow{2}{*}{ Collapsing point } & Time $(\mathrm{s})$ & 330 & 375 & 350 & 410 \\
\hline & Temperatures, $T_{\mathrm{s}}\left({ }^{\circ} \mathrm{C}\right)$ & 760 & 753 & 748 & 750 \\
\hline \multirow{2}{*}{\multicolumn{2}{|c|}{$\begin{array}{l}\text { Foaming temperature range }\left({ }^{\circ} \mathrm{C}\right) \\
\text { Porosity range, } P_{0}(\%)\end{array}$}} & $713-759$ & $696-753$ & $709-750$ & $685-750$ \\
\hline & & $60-78.7$ & $60-76$ & $50-74.4$ & $50-75.1$ \\
\hline
\end{tabular}

4.2.2. Effects of the Heating Rate on the Pore Structure. With different furnace temperatures, Figures 6 and 7 show the section photographs, corresponding to the binarizationtreated images, pore structure parameters, and its distribution of the sample in pipe $A$ at different sample temperatures.

As can be observed in Figure 9 and Table 3, the heating rate significantly affects the porosity and equivalent diameter. The general trend is that high heating rates lead to high porosity and a large equivalent diameter, but the difference is smaller than that during the free foaming process [21]. However, pipe $\mathrm{B}$ exhibits a different situation. The porosity at $740^{\circ} \mathrm{C}$ is greater than that at $760^{\circ} \mathrm{C}$, but the equivalent diameter is lower possibly because the smaller diameter of pipe $B$ exerts a higher impact on the foaming process. The effect of the heating rate on the average circularity is marginal; hence, the range and maximum value of circularity at different heating rates (furnace temperatures) are almost identical. As can be observed from the comparison between pipes $\mathrm{B}$ and $\mathrm{A}$, under the same conditions, pipe $B$ shows lower porosity and lower equivalent diameter, which may be due to the greater resistance of the pipe wall caused by the lower diameter of pipe B.

4.2.3. Analysis of the Mechanism. In the preparation of aluminum foam by the PCM method, the main foaming mechanism includes the simultaneous melting of aluminum and the decomposition of foaming agent $\mathrm{TiH}_{2}$. The higher the pyroconductivity of the matrix material and pipe is, the faster the melting temperature of the matrix material is reached at earlier time. The decomposition of $\mathrm{TiH}_{2}$ can form hydrogen gas and corresponds to endogenous foaming. The foam volume changes with time, and the whole foaming 


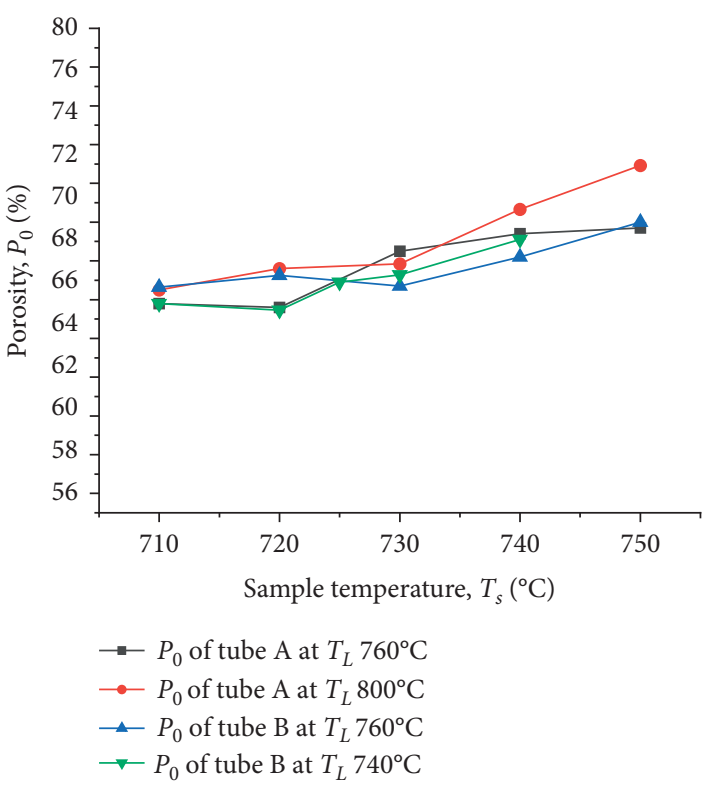

(a)

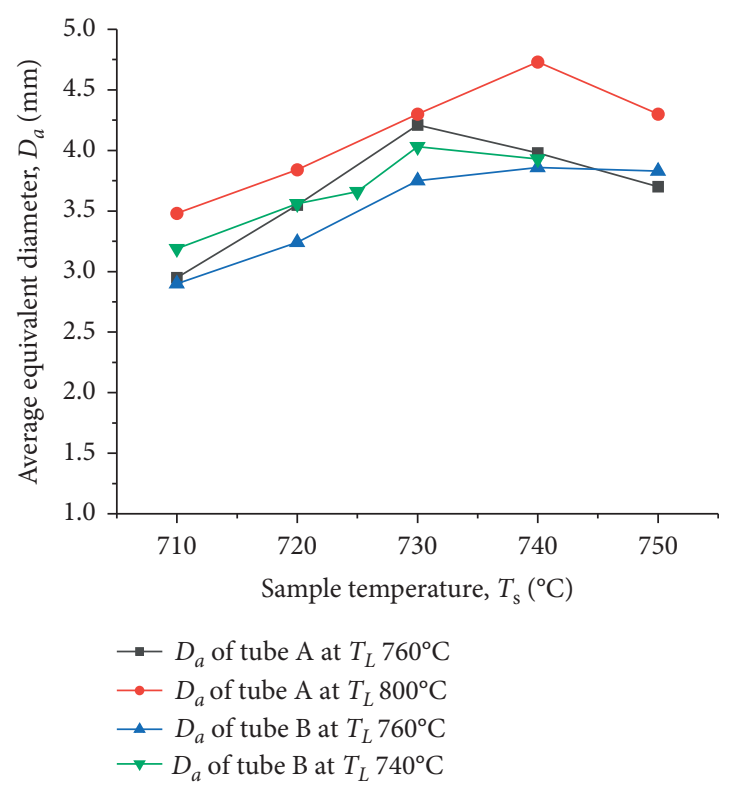

(b)

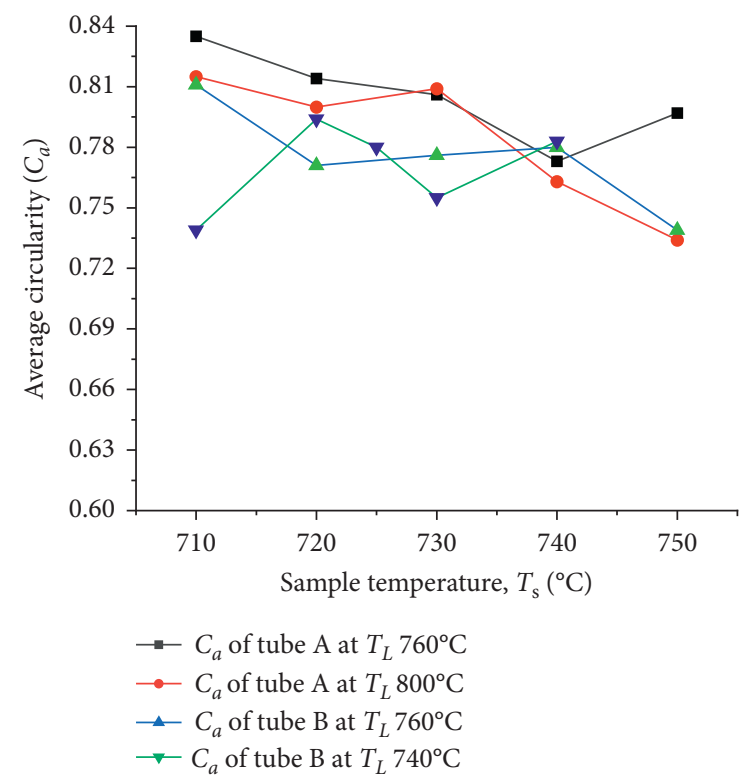

(c)

FIGURE 9: Comparison of pore structure parameters of samples in pipes A and B: (a) porosity, (b) average equivalent diameter, and (c) average circularity.

TABLE 3: The structure parameters of pores in samples at different furnace temperatures.

\begin{tabular}{|c|c|c|c|c|c|}
\hline \multirow{2}{*}{\multicolumn{2}{|c|}{ Furnace temperature $\left({ }^{\circ} \mathrm{C}\right)$}} & \multicolumn{2}{|c|}{ Pipe A } & \multicolumn{2}{|c|}{ Pipe B } \\
\hline & & 800 & 760 & 760 & 740 \\
\hline \multirow{4}{*}{\multicolumn{2}{|c|}{$\begin{array}{l}\text { Sample temperature, } T_{\mathrm{s}}\left({ }^{\circ} \mathrm{C}\right) \\
\text { Porosity, } P_{0}(\%) \\
\text { Average equivalent diameter, } D_{\mathrm{a}}(\mathrm{mm}) \\
\text { Average circularity, } C_{\mathrm{a}}\end{array}$}} & $710-750$ & $710-750$ & $710-750$ & $710-750$ \\
\hline & & $72.4-78.7$ & $69.8-76.1$ & $69.5-74.4$ & $71.0-75.1$ \\
\hline & & $2.3-3.6$ & $2.1-2.9$ & $2.3-3.4$ & $2.1-2.8$ \\
\hline & & $0.73-0.82$ & $0.78-0.84$ & $0.74-0.81$ & $0.74-0.80$ \\
\hline \multirow{4}{*}{ Maximum expansion point } & Temperature $\left({ }^{\circ} \mathrm{C}\right)$ & 740 & 730 & 740 & 740 \\
\hline & Porosity, $P_{0}(\%)$ & 78.7 & 76.1 & 74.4 & 75.1 \\
\hline & Average equivalent diameter, $D_{a}(\mathrm{~mm})$ & 3.6 & 2.7 & 2.6 & 2.5 \\
\hline & Average circularity, $C_{a}$ & 0.73 & 0.81 & 0.78 & 0.76 \\
\hline
\end{tabular}


process is a dynamic nonequilibrium process, including formation and termination. The factors that may lead to volume changes are summarized. The possible factors affecting the volume increase/loss of foamed aluminum are listed in Table 4.

Figures 2 and 3 show the foaming behavior, the expansion and foaming process, and the pore structure evolution of the aluminum foam sample prepared by the PCM method, respectively. From the point of view of physical and chemical processes, the foaming process includes the decomposition of the $\mathrm{TiH}_{2}$ foaming agent, the accumulation and nucleation of gas molecules, and the growth, variation, and collapse of pores.

$\mathrm{TiH}_{2}$ will decompose and release gas when heated to a certain temperature. Hydrogen decomposed by $\mathrm{TiH}_{2}$ is dissolved in the aluminum liquid in an atomic form at first. After reaching saturation, hydrogen will evolve as a gas and then nucleate, agglomerate, and grow in the matrix material. Therefore, pores are formed in the interior of the matrix material. Calculations and experiments indicated that loose $\mathrm{TiH}_{2}$ can spontaneously decompose when $T_{\mathrm{s}}$ is greater than $450^{\circ} \mathrm{C}[12]$. With increasing temperature, the decomposition rate of $\mathrm{TiH}_{2}$ increases correspondingly. Therefore, the decomposition amount of $\mathrm{TiH}_{2}$ increases with time and temperature. After reaching a certain temperature and time, the $\mathrm{TiH}_{2}$ content decreases; hence, the decomposition rate of $\mathrm{TiH}_{2}$ gradually decreases until the decomposition is terminated. Within the experimental temperature and time range, $\mathrm{TiH}_{2}$ was not completely decomposed [12].

As hydrogen gas forms pores and pores grow in liquid metal, the pressures experienced include air pressure, metal static pressure, the additional pressure generated by surface tension, and the resistance caused by the viscosity of liquid metal. Therefore, the nucleation and growth of pores must comply with the following equation [24]:

$$
P>P_{\mathrm{ex}}=P_{1}+\rho g h+\frac{2 \sigma}{r}+\frac{F}{\pi r^{2}},
$$

where $P$ is the pressure inside hydrogen gas, $\mathrm{Pa} ; P_{1}$ is the air pressure, constant, $\mathrm{Pa} ; \rho$ is the density of liquid, $\mathrm{kg} / \mathrm{m}^{3} ; g$ is the acceleration of gravity, $\mathrm{m} / \mathrm{s}^{2} ; h$ is the length of liquid above the pores, $\mathrm{m} ; \sigma$ is the liquid-gas surface tension (energy), N/m; $r$ is the pore diameter, $\mathrm{m}$; and $F$ is the viscous force of liquid metal. The force originates from the viscosity.

Therefore, it exhibits a clear impact at low temperatures, and its effect rapidly decreases with increasing temperature. $F=f(\eta)$, N.

Meanwhile, the growth of gas inside pores also conforms to the state equation of an ideal gas at a constant temperature:

$$
P V=n R T,
$$

where $P$ is the internal pressure of hydrogen gas, $\mathrm{Pa} ; V$ is the volume of hydrogen gas inside foams, $\mathrm{m}^{3} ; n$ is the moles of hydrogen gas, mol; $R$ is the gas constant; and $T$ is the temperature, $\mathrm{K}$.
The volume variation during foaming can be considered as the sum of volume gain (VG) and volumetric loss (VL), which can be expressed as follows:

$$
\begin{aligned}
& \frac{\partial v}{\partial t}=\frac{\partial V_{\mathrm{VG}}}{\partial t}-\frac{\partial_{\mathrm{VL}}}{\partial t}, \\
& \frac{\partial V}{\partial t}=\frac{\partial}{\partial t}\left(V_{\mathrm{HP}}+V_{\mathrm{GE}}-V_{\mathrm{HD}}-V_{\mathrm{BR}}\right),
\end{aligned}
$$

where $V_{\mathrm{HP}}$ denotes the expanded gas volume caused by hydrogen gas (HP) produced by the decomposition of $\mathrm{TiH}_{2}$; $V_{\mathrm{GE}}$ denotes the expansion caused by the rising temperature of the sample $\left(T_{\mathrm{s}}\right) ; V_{\mathrm{HD}}$ represents volume loss caused by hydrogen diffusion and overflow; and $V_{\mathrm{BR}}$ indicates the volume reduction loss caused by surface bubble fracture.

Combined with the data summarized in Table 3, the sample temperature affects the foaming process by affecting the decomposition rate on the $\mathrm{TiH}_{2}$ foaming agent, the viscosity of the sample, and the expansion of gas. $\mathrm{TiH}_{2}$ begins to decompose at temperatures greater than $400^{\circ} \mathrm{C}$ and rapidly decomposes at temperatures greater than $600^{\circ} \mathrm{C}$. As the temperature is less than the melting point $\left(660^{\circ} \mathrm{C}\right)$, the sample is still in the solid state, so it is unlikely to expand and foam. As the temperature reaches the melting point, the sample begins to melt, and its viscosity decreases. As can be observed from formula (1), if the hydrogen pressure is greater than the external pressure, the sample begins to expand, and foaming is observed; however, within the plateau zone of the temperature curve of the sample (heating time >100s), the temperature changes slightly, and the viscosity slowly increases due to endothermic characteristics of the melting process. Hence, the expansion caused by foaming is unclear. As the temperature exceeds the plateau, the temperature of the sample increases rapidly with the extension of heating time; the sample viscosity decreased rapidly, and the decomposition rate of the foaming agent $\mathrm{TiH}_{2}$ increased. Despite hydrogen evolution and bubble collapse, it still meets the requirements of accelerating expansion, so the porosity increases rapidly. When the temperature rises to a certain value $\left(700^{\circ} \mathrm{C}\right), V_{\mathrm{HP}}$ caused by the $\mathrm{TiH}_{2}$ decomposition considerably decreases, and the viscosity of the sample drastically decreases, leading to considerable gas evolution as well as the discharge of liquid between the bubbles [23, 25, 26]; hence, bubbles start to merge and disappear. Currently, the sample begins to collapse, the volume decreases, and the foaming process is over. On the contrary, high temperature also indicates the extension of the heating time, which is beneficial for the decomposition of $\mathrm{TiH}_{2}$, and strengthening of the growth and merging of pores, even the gas overflow. All in all, these behaviors have a complex influence on the foaming behavior and pore structure.

The higher the furnace temperature, the higher the heating rate of the sample and the shorter the time needed to reach the same temperature. Hence, $V_{\mathrm{HD}}$ caused by the hydrogen evolution during the $\mathrm{TiH}_{2}$ decomposition decreases. At the same time, it reduces the probability of bubble burst and merger, that is, it improves the utilization ratio. Therefore, the system can achieve a high expanded volume. 
TABle 4: Possible mechanisms and their contribution to the volume gain/loss during foaming [23].

\begin{tabular}{lc}
\hline Foaming and expansion & Influencing factors \\
\hline Volume gain $(\mathrm{VG})$ & $\begin{array}{c}\text { Gas expansion caused by hydrogen gas produced by TiH } \mathrm{T}_{2} \text { decomposition }(\mathrm{HP}) \\
\text { Gas expansion }(\mathrm{GE}) \text { corresponded to the temperature rise of the sample }\left(T_{\mathrm{s}}\right)\end{array}$ \\
\hline Volume loss $(\mathrm{VL})$ & $\begin{array}{c}\text { Volume loss during the diffusion and overflow process of hydrogen gas (HD) } \\
\text { Volume loss during the fracture of surface bubbles (BR) }\end{array}$ \\
\hline
\end{tabular}

At a low heating rate, $V_{\mathrm{HD}}$ increases, expansion volume decreases, and porosity decreases due to hydrogen evolution during the $\mathrm{TiH}_{2}$ decomposition.

\section{Conclusions}

It is obvious from the results presented that the heating time and the heating rate are the principal factors that affect the foaming behavior and pore structure of aluminum foam. Owing to the limitation of the pipe diameter, the maximum expansion height and porosity are constrained, while the pore size, shape uniformity, and circularity of pores are better than those during free foaming. Under the experimental conditions, the sample can foam and completely fill the steel pipe within the furnace temperature range of $740^{\circ} \mathrm{C}-800^{\circ} \mathrm{C}$; the aluminum foam with a porosity of $70 \%-$ $79 \%$, an equivalent-circle diameter of $2.1 \mathrm{~mm}-3.6 \mathrm{~mm}$, and a circularity of $0.73-0.84$ can be obtained. The maximum expansion temperature (full filling of the pipe) is between $730^{\circ} \mathrm{C}$ and $740^{\circ} \mathrm{C}$, so the optimum temperature for producing aluminum foam is $730^{\circ} \mathrm{C}$ and $740^{\circ} \mathrm{C}$.

In the preparation of the aluminum foam by using the PCM method, the decomposition of hydride $\left(\mathrm{TiH}_{2}\right)$ to generate hydrogen gas is the main foaming mechanism. The entire foaming process is a dynamic nonequilibrium process comprising the formation and collapse of foams. The process is mainly influenced by four parameters, namely, $V_{\mathrm{HP}}, V_{\mathrm{GE}}$, $V_{\mathrm{HD}}$, and $V_{\mathrm{BR}}$, among which the volume change of foam is more influenced by $\mathrm{H}_{2}$ released during the decomposition process of $\mathrm{TiH}_{2}$. Meanwhile, the possibility of merger and collapse is reduced, which indicates high utilization efficiency and large expansion volume.

\section{Data Availability}

The data used to support the findings of this study are included within the article.

\section{Conflicts of Interest}

The authors declare that they have no conflicts of interest.

\section{Acknowledgments}

This study was supported by the Natural Science Foundation of Shanxi Province, China (Grant no. 201901D111270) and Key R\&D Project of Shanxi Province (high-tech), China (Grant no. 201803D121004).

\section{References}

[1] J. Banhart, J. Baumeister, and M. Weber, "Damping properties of aluminium foams," Materials Science and Engineering: A, vol. 205, no. 1-2, pp. 221-228, 1996.

[2] J. Baumeister, J. Banhart, and M. Weber, "Aluminium foams for transport industry," Materials \& Design, vol. 18, no. 4-6, pp. 217-220, 1997.

[3] F. Han, Z. Zhu, and J. Gao, "Compressive deformation and energy absorbing characteristic of foamed aluminum," Metallurgical and Materials Transactions A, vol. 29, no. 10, pp. 2497-2502, 1998.

[4] M. F. Ashby, T. Evans, N. A. Fleck et al., Metal Foams A Design Guide, Society of Automotive Engineers Inc, Warrendale, PA, USA, 2000

[5] J. Banhart, D. Bellmann, and H. Clemens, "Investigation of metal foam formation by microscopy and ultra small-angle neutron scattering," Acta Materialia, vol. 49, no. 17, pp. 3409-3420, 2001.

[6] G. Ryan, A. Pandit, and D. P. Apatsidis, "Fabrication methods of porous metals for use in orthopaedic applications," Biomaterials, vol. 27, no. 13, pp. 2651-2670, 2006.

[7] J. Banhart, G. S. Vinod-Kumar, P. H. Kamm, T. R. Neu, and F. García-Moreno, "Light-metal foams: some recent developments," Ciência \& Tecnologia Dos Materiais, vol. 28, no. 1, pp. 1-4, 2016.

[8] M. Mukherjee, F. García-Moreno, C. Jiménez, A. Rack, and J. Banhart, "Microporosity in aluminium foams," Acta Materialia, vol. 131, pp. 156-168, 2017.

[9] H.-P. Degischer and B. Kriszt, Handbook of Cellular Metals_ Production, Processing, Applications, Wiley VCH, Hoboken, NJ, USA, 2002.

[10] N. Babcsán, D. Leitlmeier, and J. Banhart, "Metal foams-high temperature colloids," Colloids and Surfaces A: Physicochemical and Engineering Aspects, vol. 261, no. 1-3, pp. 123-130, 2005.

[11] N. Babcsán, F. G. Moreno, and J. Banhart, "Metal foams-high temperature colloids," Colloids and Surfaces A: Physicochemical and Engineering Aspects, vol. 309, no. 1-3, pp. 254263, 2007.

[12] M. A. Carolin K"orner and R. F. Singer, "Metal foam stabilization by oxide network," Materials Science and Engineering, vol. 396, pp. 28-40, 2005.

[13] I. Duarte and M. Oliveira, Aluminium Alloy Foams: Production and Properties, P. Metallurgy and Dr. Katsuyoshi Kondoh, Eds., InTechOpen, London, UK, 2012.

[14] K. Heim, G. S. V. Kumar, F. Garcia-Moreno, I. Manke, and J. Banhart, "Drainage of particle-stabilised aluminium composites through single films and plateau borders," Colloids and Surfaces A: Physicochemical and Engineering Aspects, vol. 438, pp. 85-92, 2013.

[15] A. KOVAČIČ, Computer Modelling of Porous Composite Structures with Advanced Pore Morphology, University of Maribor, Maribor, Slovenia, 2016. 
[16] A. Rajaneesh, I. Sridhar, and S. Rajendran, "Impact modeling of foam cored sandwich plates with ductile or brittle faceplates," Composite Structures, vol. 94, no. 5, pp. 1745-1754, 2012.

[17] J. Baumeister, J. Weise, E. Hirtz, K. Höhne, and J. Hohe, "Applications of aluminum hybrid foam sandwiches in battery housings for electric vehicles," Procedia Materials Science, vol. 4 , pp. 317-321, 2014.

[18] T. Hipke, J. Hohlfeld, and S. Rybandt, "Functionally aluminum foam composites for building industry," Procedia Materials Science, vol. 4, pp. 133-138, 2014.

[19] I. Elnasri and H. Zhao, "Impact perforation of sandwich panels with aluminum foam core: a numerical and analytical study," International Journal of Impact Engineering, vol. 96, pp. 50-60, 2016.

[20] I. Duarte, L. Krstulović-Opara, and M. Vesenjak, "Characterisation of aluminium alloy tubes filled with aluminium alloy integral-skin foam under axial compressive loads," Composite Structures, vol. 121, pp. 154-162, 2015.

[21] L. Wang, M. Lv, F. Wang et al., "Foaming behavior and evolution of cell structure of foamed aluminum with extrusion forming precursor under unconstrained condition," Foundry, vol. 64, no. 10, pp. 945-949, 2015, in Chinese.

[22] J. Banhart, "Manufacture, characterisation and application of cellular metals and metal foams," Progress in Materials Science, vol. 46, no. 6, pp. 559-632, 2001.

[23] M. Mukherjee, F. Garcia-Moreno, and J. Banhart, "Solidification of metal foams," Acta Materialia, vol. 58, no. 19, pp. 6358-6370, 2010.

[24] K. Wu, Fundamental Theory on Melts of Bubble Metallurgy, Metallurgical Industry Press, Beijing, Chian, 2000, in Chinese.

[25] A. Haibel, A. Rack, and J. Banhart, "Why are metal foams stable?" Applied Physics Letters, vol. 89, no. 15, 2006.

[26] F. García-Moreno, P. H. Kamm, T. Neu, K. Heim, A. Rack, and J. Banhart, "In situ X-ray tomography of aqueous foams: analysis of columnar foam generation," Colloids and Surfaces A: Physicochemical and Engineering Aspects, vol. 534, pp. 78-84, 2017. 